\title{
Synthesis and characterization of polyaniline composite with shell membrane
}

\author{
Yuki Kaitsuka, Hiromasa Goto* \\ Division of Materials Science, Faculty of Pure and Applied Sciences, University of \\ Tsukuba, Tsukuba Ibaraki 305-8573, Japan
}

\begin{abstract}
Polyaniline (PANI) and shell membrane composites have been synthesized via chemical oxidative polymerization of aniline in the presence of shell membrane. Combination of surfactant, PANI, and shell membrane allows production of conductive textile with smooth surface. Fourier transform infrared spectroscopy (FTIR) measurements suggest that the oxidation degree of PANI was affected by the initial ratio of shell membrane vs. monomer amount. The PANI/shell membrane composites were characterized with UV-vis absorption spectroscopy, electron spin resonance (ESR) spectroscopy (ESR).Electrical conductivity of the composites was measured with four-probe method. The surface of the composites was observed with scanning electron microscopy (SEM). Thermal stability of the composites was discussed with the result of thermogravimetric analysis.
\end{abstract}

\section{Introduction}

Conductive polymers [1] have attracted significant attention in recent decades because of many practical applications in various fields such as electrochromism and sensors [2]. Polyaniline (PANI), one of the most promising conductive polymers, has great interest due to low cost production and convenient preparation in water medium, environmental stability, and good redox property [3-7]. Synthesis of PANI composite is expected as the suitable way to improve its processing and mechanical properties [8-11]. Moreover, the carbonization of PANI have been widely studied for creating the fine structure and unique properties $[12,13]$.

In this research, PANI/shell membrane composites were prepared oxidative reaction in water. Shell membrane (thin film inside of shell) of hen egg has multi-layer structure consisting of protein. The thickness of membrane is ca. 20-70 $\mu \mathrm{m}$ (Figure 1) [14]. Due to their unique property, shell membrane has been studied for applications as biomaterials by using its semi-permiability, such as a wound dressing [15-19]. However, there are few reports on PANI/shell membrane composite [20]. Here, we examined its properties and morphology, and discuss on polymerization condition on the surface of 
the shell membrane.
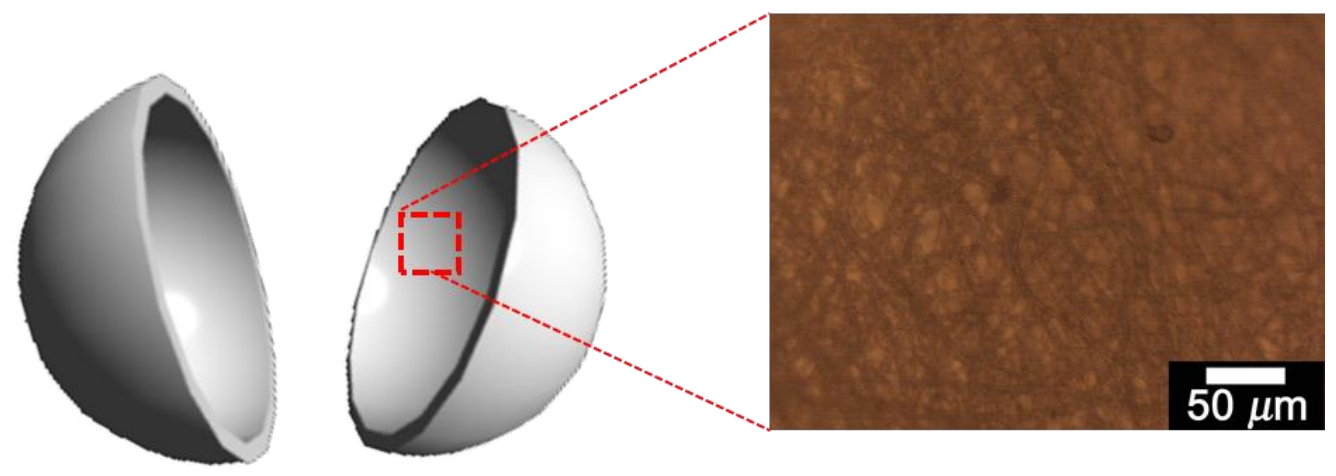

Figure 1. Plausible structure of egg (left) and POM image of shell membrane (right).

Synthesis

Distilled aniline, sulfuric acid (or sodium dodecyl benzenesulphonate (SDBS)) and shell membrane were stirred in vial (the quantities are listed in Table 1). The mixture was cooled to $0 \mathrm{oC}$ and stirred for $1 \mathrm{~h}$. Then, a solution of ammonium peroxodisulfate (APS) dissolved in minimum amount of water was dropped into the mixture. After reacted for $24 \mathrm{~h}$, the dark green precipitate was washed into a large volume of water. After filtration collected cake was washed with large amount of methanol followed by filtration. The product was dried under vacuum to afford a black powder. The polymerizations are summarized in Table 1. The composites are abbreviated as PANI-M1-6.

\section{Characterization}

IR absorption spectroscopy measurements were conducted using a Thermo Scientific NICOLET iS5 (Thermo Fisher Scientific, Kanagawa, Japan) with the KBr method. UV-vis spectroscopy was recorded on a JASCO V-630 (JASCO, Tokyo, Japan) spectrophotometer. SEM observations were performed with a JEOL JSM-7000F (JEOL, Tokyo, Japan). The surfaces of shell membrane and composites were sputtered with gold by a JEOL JFC-1500 (Japan). ESR measurements were carried out by a Bruker EMX-T ESR spectrometer (Massachusetts, USA). Electrical conductivity was measured by four-probe method using Mitsubishi Chemical Analytech LORESTA-GP MCP-T610 (Mitsubishi Chemical Analytech, Chigasaki, Japan). Thermogravimetric analysis (TGA) was conducted by a Seiko Instruments Inc. EXSTAR7000 (Chiba, Japan). 
Table 1. Preparation of PANI/shell membrane and $\mathrm{PANI} / \mathrm{H}_{2} \mathrm{SO}_{4}$.

\begin{tabular}{|c|c|c|c|c|c|c|}
\hline Polymer & $\begin{array}{c}\text { Aniline } \\
(\mathrm{mg}, \mathrm{mmol})^{\mathrm{a}}\end{array}$ & $\begin{array}{c}\text { Shell } \\
\text { membrane } \\
(\mathrm{mg})\end{array}$ & $\begin{array}{l}\text { Aniline/shell } \\
\text { membrane } \\
(\text { feed } \%)\end{array}$ & $\begin{array}{c}\text { Acid } \\
(\mathrm{mg}, \mathrm{mmol})^{\mathrm{a}}\end{array}$ & $\begin{array}{c}\text { APS } \\
(\mathrm{mg}, \\
\mathrm{mmol}^{\mathrm{a}}\end{array}$ & $\begin{array}{l}\text { Product } \\
(\mathrm{mg})\end{array}$ \\
\hline PANI-M1 & $10.4,0.112$ & 101.1 & 10.3 & $\begin{array}{l}\mathrm{H}_{2} \mathrm{SO}_{4} \\
(21.3, \\
0.206)\end{array}$ & $\begin{array}{l}30.4 \\
0.133\end{array}$ & 87.3 \\
\hline PANI-M2 & $9.60,0.103$ & 21.30 & 45.0 & $\begin{array}{c}\mathrm{H}_{2} \mathrm{SO}_{4} \\
(5.68 \\
0.0550)\end{array}$ & $\begin{array}{l}30.0 \\
0.131\end{array}$ & 20.6 \\
\hline PANI-M3 & $11.4,0.122$ & 10.5 & 108.6 & $\begin{array}{c}\mathrm{H}_{2} \mathrm{SO}_{4} \\
(5.89 \\
0.0570)\end{array}$ & $\begin{array}{l}29.7 \\
0.130\end{array}$ & 8.8 \\
\hline PANI-M4 & $17.0,0.183$ & 11.70 & 145.2 & $\begin{array}{c}\mathrm{H}_{2} \mathrm{SO}_{4} \\
(2.84, \\
0.0275)\end{array}$ & $\begin{array}{l}45.1 \\
0.197\end{array}$ & 13.2 \\
\hline PANI-M5 & $41.3,0.443$ & 21.00 & 196.7 & $\begin{array}{l}\mathrm{H}_{2} \mathrm{SO}_{4} \\
(23.5 \\
0.228)\end{array}$ & $\begin{array}{l}118.8 \\
0.520\end{array}$ & 37.7 \\
\hline PANI-M6 & $10.9,0.117$ & 10.30 & 105.8 & $\begin{array}{l}\text { SDBS } \\
(39.4, \\
0.113)\end{array}$ & $\begin{array}{l}49.3 \\
0.216\end{array}$ & 13.0 \\
\hline $\begin{array}{l}\text { pure } \\
\text { PANI }\end{array}$ & $2004,21.5$ & - & - & $\begin{array}{c}\mathrm{H}_{2} \mathrm{SO}_{4} \\
(1175,11.4)\end{array}$ & $589,25.8$ & 2017 \\
\hline
\end{tabular}

${ }^{\mathrm{a}}$ Sample weight and mole amount.

IR

IR absorption spectroscopy measurements with the $\mathrm{KBr}$ method were performed for shell membrane, PANI-M1, PANI-M2, PANI-M3, PANI-M4, PANI-M5 and pure PANI to confirm chemical structure (Figure 2). Absorption bands corresponding to protein, amide I,II and III are observed at 1659, 1535, and $1243 \mathrm{~cm}^{-1}$, respectively (Figure 2) [21]. Amide I represents absorption band of $\mathrm{C}=\mathrm{O}$ stretching. An absorption band of Amide II arises from N-H bending coupled to $\mathrm{C}-\mathrm{N}$ stretching. Amide III contains vibrations of $\mathrm{C}-\mathrm{N}$ stretching and $\mathrm{N}-\mathrm{H}$ in-plane bending. The composites possess absorption bands at $1659 \mathrm{~cm}-1$ ( $\mathrm{C}=\mathrm{O}$ stretching). Furthermore, PANI-M3, PANI-M4, and PANI-M5 showed typical absorption bands of PANI at $1572 \mathrm{~cm}^{-1}$ (quinoid (Q) $\mathrm{C}=\mathrm{C}$ stretching), $1498 \mathrm{~cm}^{-1}$ (benzenoid (B) $\mathrm{C}=\mathrm{C}$ stretching), $1299 \mathrm{~cm}^{-1}$ (vQBQ C-N stretching), $1249 \mathrm{~cm}^{-1}$ ( $v_{\mathrm{BBB}} \mathrm{C}-\mathrm{N}$ stretching), and $1125 \mathrm{~cm}-1 \quad\left(v_{\mathrm{QBQ}} \mathrm{C}=\mathrm{N}\right.$ stretching) [9]. Some absorption bands at $1572 \mathrm{~cm}-1\left(v_{\mathrm{Q}}\right)$ and $1498 \mathrm{~cm}-1\left(v_{\mathrm{B}}\right)$ are shifted to high wavenumbers compared with pure PANI because of interaction between PANI and shell membrane. On the other hand, the IR absorption intensity of PANI-M1 
and PANI-M2 originated from basic structure of aniline unit is weaker than that of other composites however both composites have absorption band at $1120 \mathrm{~cm}^{-1}\left(v_{\mathrm{QBQ}} \mathrm{C}=\mathrm{N}\right.$ stretching). These results confirm formation of PANI/shell membrane.

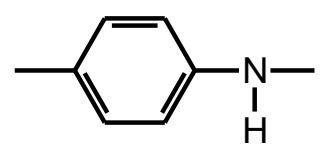

Benzenoid (B)

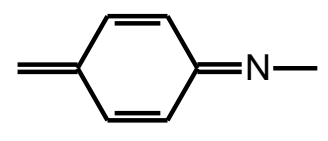

Quinoid (Q)

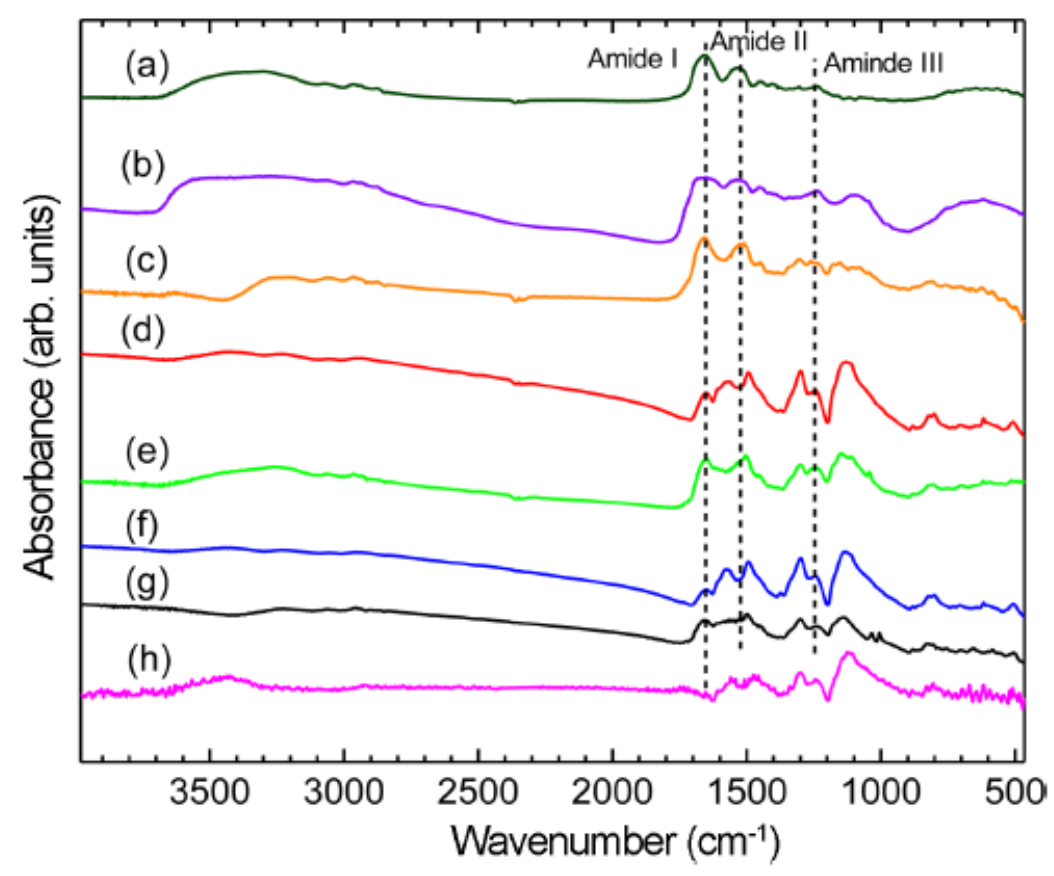

Figure 2. Fourier transform infrared (FTIR) spectra of (a) shell membrane, (b) PANI-M1, (c) PANI-M2, (d) PANI-M3, (e) PANI-M4, (f) PANI-M5, (g) PANI-M6, and (h) pure PANI.

Morphology

Scanning electron microscopy (SEM) images of the composite surface of shell membrane, PANI-M3, PANI-M5 and pure PANI are shown in Figure 3. A pure PANI shows granular structure, as shown in Figure 3 (b) [9]. The SEM result implies the deposition of PANI on shell membrane [20]. Furthermore, granular PANI forms were observed on the shell membrane fiber covered with PANI. 


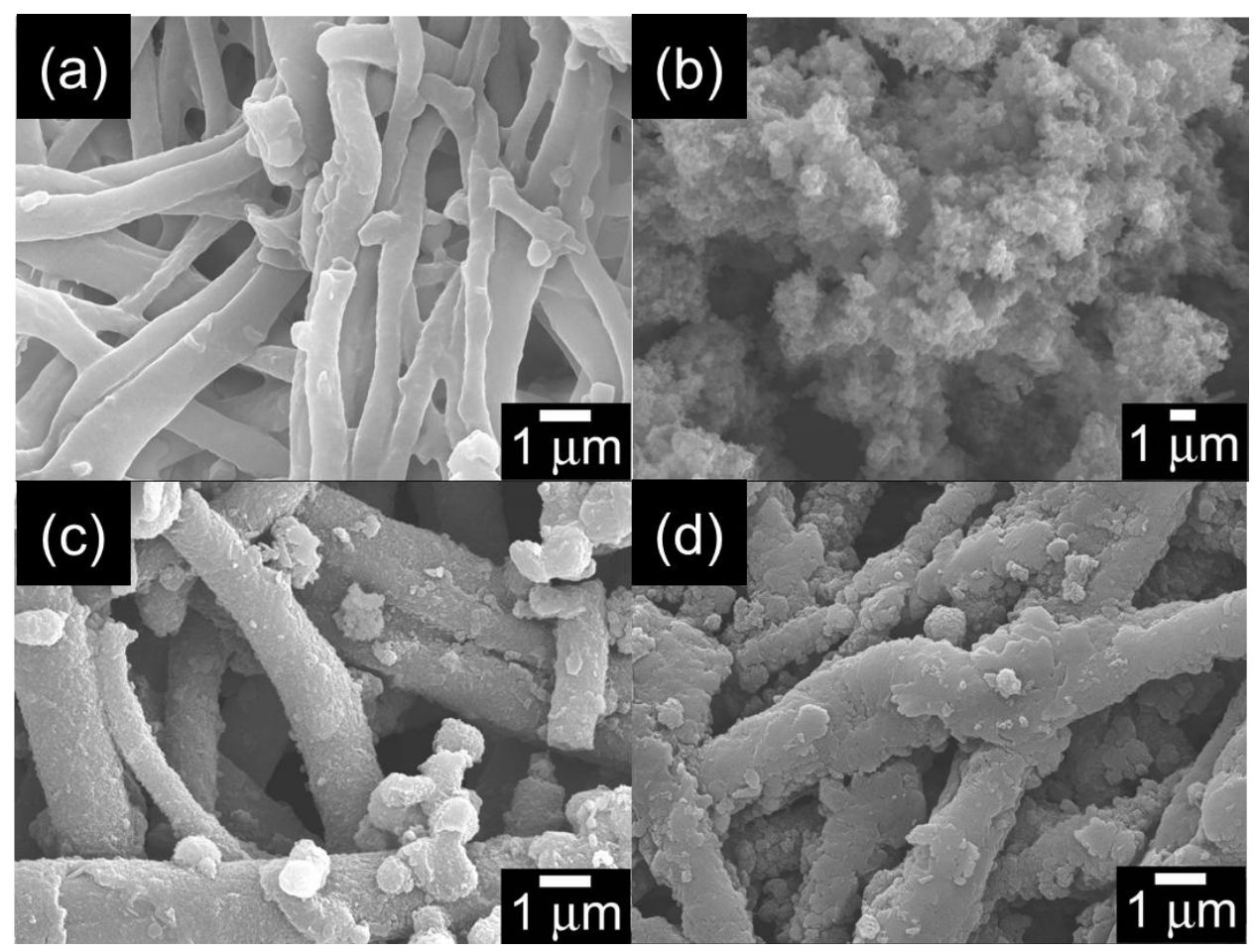

Figure 3. SEM images of Shell membrane (a), pure PANI(b), PANI-M3 (c) and PANI-M5(d).

Magnetic property

In-situ ESR spectra of PANI-M1, PANI-M2, PANI-M3, PANI-M4, PANI-M5 and pure PANI were conducted (Figure 4). The existence of radicals as charge careers in these polymers is indicated from these spectra. The g-value, line with $\left(\Delta H_{\mathrm{pp}}\right)$, spin concentration and electrical conductivity of the samples are summarized in Table 2.The g-values of the samples are half-position between g-values of electron near a nitrogen-hydrogen bond $(g=2.0054)$ and carbon-hydrogen bond $(g=2.0031)$ [22] (Table 2). All composites except for PANI-M4 have a tendency to increase g-value and decrease spin concentration and electrical conductivity as increasing the ratio of shell membrane. A narrow peak-to-peak line-width suggests high carrier (polarons, radical cations) mobility [23]. PANI-M3, PANI-M4 and PANI-M5 show narrow $\Delta H_{\mathrm{pp}}$. In case of the composite, the main-chain of PANI can be linear form such as expanded coil as the secondary doping due to interaction between PANI and shell membrane [24]. 


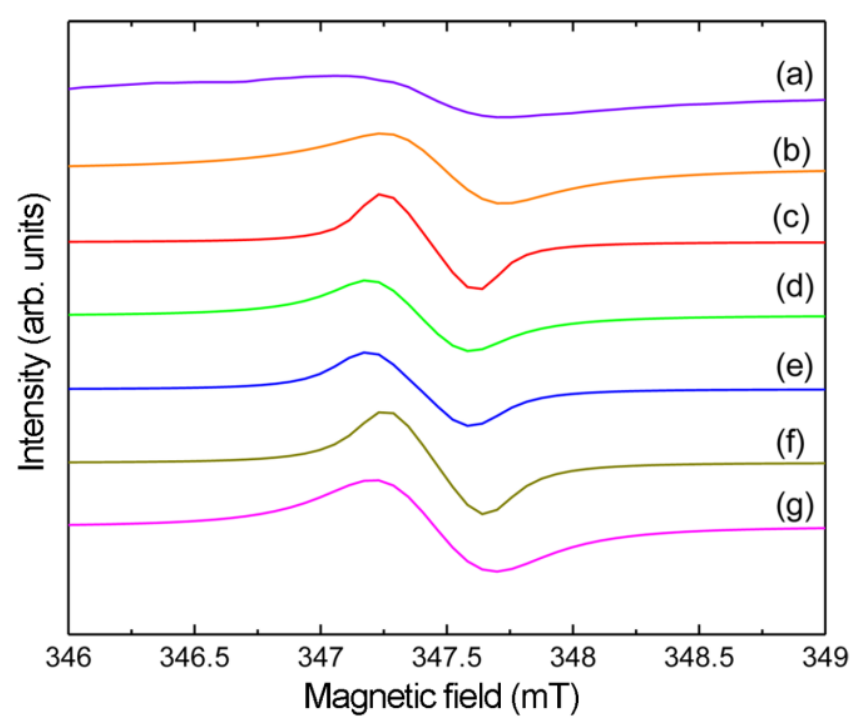

Figure 4. Electron spin resonance (ESR) spectra of (a) PANI-M1, (b)PANI-M2, (c)PANI-M3, (d)PANI-M4, (e) PANI-M5, (f) PANI-M5, and (g) pure PANI.

Table 2. ESR results and electrical conductivity.

\begin{tabular}{ccccc}
\hline Polymer & g-value & $\begin{array}{l}\Delta H_{\mathrm{pp}} \\
(\mathrm{mT})\end{array}$ & Ns (spins/g) & $\sigma(\mathrm{S} / \mathrm{cm})$ \\
\hline PANI-M1 & 2.00442 & 0.645 & $1.12 \times 10^{18}$ & $2.40 \times 10^{-7}$ \\
PANI-M2 & 2.00399 & 0.469 & $1.87 \times 10^{19}$ & $7.19 \times 10^{-7}$ \\
PANI-M3 & 2.00342 & 0.410 & $5.54 \times 10^{19}$ & $8.32 \times 10^{-4}$ \\
PANI-M4 & 2.00454 & 0.410 & $3.38 \times 10^{19}$ & $4.07 \times 10^{6}$ \\
PANI-M5 & 2.00315 & 0.352 & $6.67 \times 10^{19}$ & $1.09 \times 10^{-3}$ \\
Pure PANI & 2.00331 & 0.469 & $1.36 \times 10^{20}$ & 3.52 \\
\hline
\end{tabular}

TG

The thermal behavior of shell membrane, PANI-M1, PANI-M2, PANI-M3, PANI-M4, and pure PANI was examined with thermogravimetric analysis (TGA). All samples are held at $120{ }^{\circ} \mathrm{C}$ for 10 minutes to exclude water in them. The TGA results are summarized in Figure 5(a). The weight loss occurred between 165 and 300oCis explained by the release of the dopant. In the temperature range of $330-680{ }^{\circ} \mathrm{C}$, a distinct mass loss was exhibited because of degradation of the skeletal PANI chain structure.[25,26]The degradation of the shell membrane was seen in the temperature range of $220-515{ }^{\circ} \mathrm{C}$ [21]. Temperature of $5 \%$ weight loss vs. shell membrane component (wt\%) in the composite is plotted in Figure5 (b). Thermal stability is strengthened through formation of the composite. 

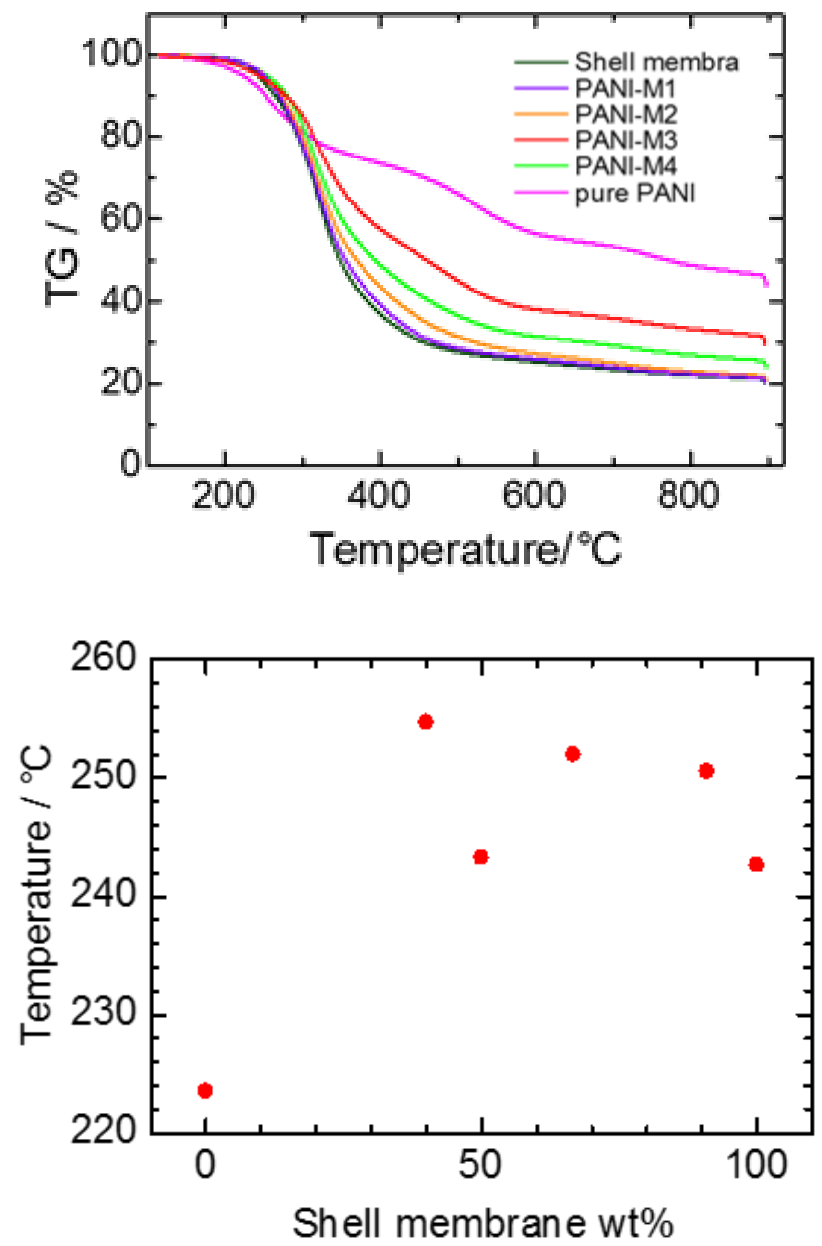

(b)

Figure 5. (a) TGA curves of shell membrane, PANI-M1, PANI-M2, PANI-M3, PANI-M4, and polyaniline; (b) plot of 5\% weight reduction temperature of the composites prepared at different weight percentage of shell membrane

Morphology after carbonization

Surface images obtained with scanning electron microscopy (SEM) of the carbonized composite from PANI-M3 and PANI-M2are displayed in Figure 6. Carbonization of composite was carried out at $900{ }^{\circ} \mathrm{C}$ in an argon atmosphere. Carbonized PANI forms granular structure. The form of the shell membrane was maintained after carbonization [27]. The carbon maintains the morphology of the composite as a precursor after the thermal carbonized reaction. This fiber-shaped carbon is originated from polyaniline deposited on shell membrane. All samples shrink after carbonization. The size of the samples is decreased ca. 20-30\% after carbonization. 


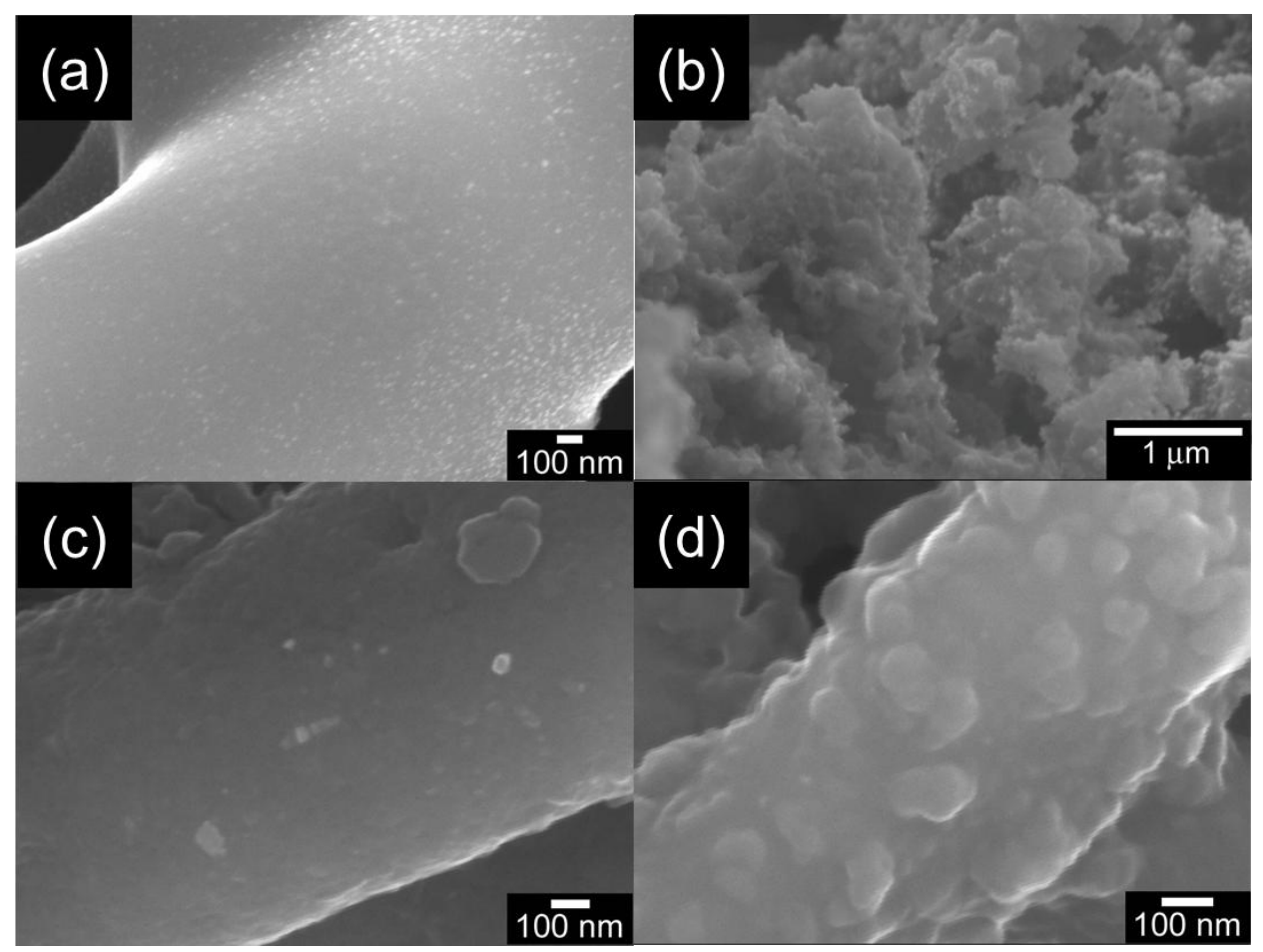

Figure 6. SEM images of (a) carbonized shell membrane, (b) carbonized pure PANI, (c) carbonized PANI-M3, and (d) carbonized PANI-M2.

The effect of surfactant

Scanning electron microscopy (SEM) images of the carbonized composite surface of PANI-M3 and PANI-M6are shown in Figure 7. PANI-M6 was synthesized by using SDBS in place of sulfuric acid. SDBS is expected to behave as surfactant and support adhesion of PANI on shell membrane fiber. Aniline is polymerized in the form of micelle consisting of SDBS and pure PANI. The forming micelle restrained to form bulk aggregate. Shell membrane fiber should be covered with PANI smoothly and uniformly after the micelle polymerization.

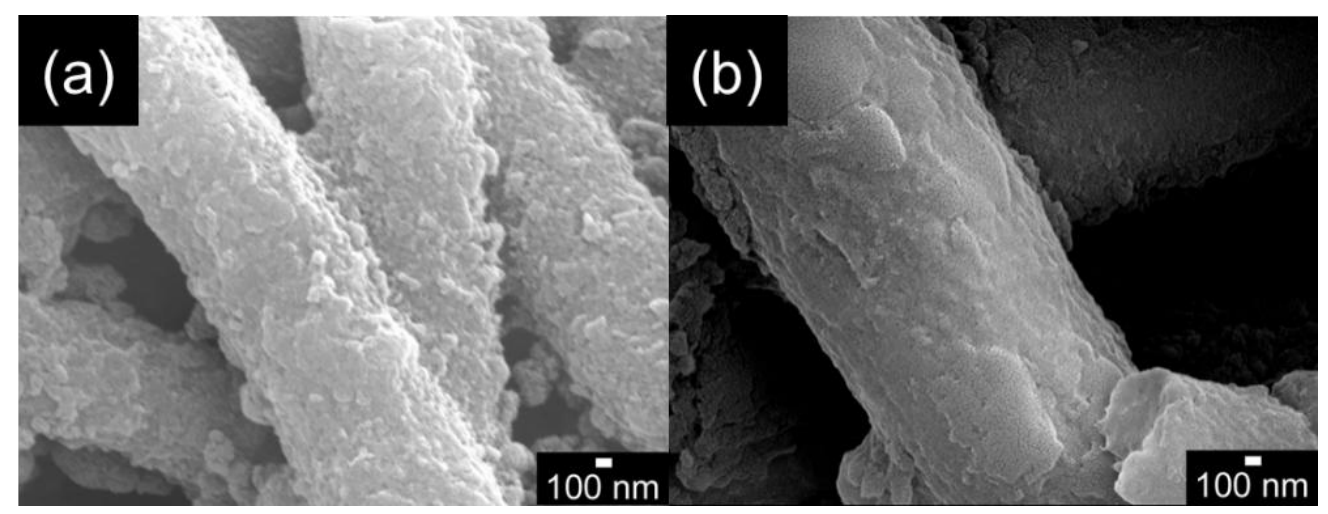

Figure 7. SEM images of (a) PANI-M3 and (b) PANI-M6. 
Mechanism

Aniline sulfonic salt can be absorbed into the shell membrane by capillary effect [28]. The aniline molecules are arranged along the membrane prior to polymerization because of the intermolecular hydrogen bonding, or electrostatic interaction between aniline molecules and the protein of the shell membrane [13]. The main chain enlarges along the fibered surface of the shell membrane due to intermolecular interactions. Then polymer on shell membrane formed linear chain such as expanded coil as a concept of secondary doping [24], and occurrence of $\pi-\pi$ stacking of benzene ring between adjacent PANI chains. Mobility of the charge in the composites can be increased through preparing the composite. Furthermore, terminal groups like $\mathrm{SH}$ form cystine can help to construct intra-molecular interactions with PANI to promote multilayer assembly of PANI around the egg shell membrane fibers [29]. This can be referred to as "textile aided secondary doping".

\section{Conclusion}

PANI/shell membrane composites were synthesized through oxidative chemical polymerization. Spectral data suggest occurrence of secondary doping on the textile in the polymerization. TG analysis found to be the composite improves thermal stability due to interaction between PANI and shell membrane. SDBS as a surfactant produces the PANI composite with smooth surface.

\section{Acknowledgement}

We thank Chemical Analysis Division Research Facility Center for Science and Technology of University of Tsukuba for ESR measurements and TGA. IR measurements were conducted in Kijima laboratory of University of Tsukuba. We would like to thank National Institute for Materials Science (NIMS) microstructural characterization platform for obtaining SEM images. We thank Dr. Takeguchi (Station Director, Transmission Electron Microscopy Station, RNFS, NIMS). This research was supported by Tsukuba Research Center for Interdisciplinary Materials Science (TIMS).

\section{References}

[1] A.G. MacDiarmid, Synthetic Metals": A Novel Role for Organic Polymers (Nobel Lecture), Angew. Chem. Int. Ed. Engl. 40 (2001) 2581-2590.

[2] G. Yuan, N. Kuramoto, "Synthesis of Helical Polyanilines Using Chondroitin Sulfate 
as a Molecular Template,” Macromol. Chem. Phys. 205 (2004) 1744-1751.

[3] A.G. MacDiarmid, J.C. Chiang, A.F. Richter, "Polyaniline: a new concept in conducting polymers," Synth. Met. 18 (1987) 285-290.

[4] N. Gospodinova, L. Terlemezyan, "Conducting polymers prepared by oxidative polymerization: polyaniline,” Prog. Polym. Sci., 23 (1998) 1443-1484.

[5] J.C. Chiang, A.G. MacDiarmid, "Polyaniline': Protonic acid doping of the emeraldine form to the metallic regime," Synth. Met. 13 (1986) 193-205.

[6] C.T. Kuo, S.Z. Weng, R.L. Huang, "Field-effect transistor with polyaniline and poly(2-alkylaniline) thin film as semiconductor,” Synth. Met. 88 (1997) 101-107.

[7] B. Bahmani, F. Moztarzadeh, M. Rabiee, M. Tahriri, "Development of an electrochemical sulfite biosensor by immobilization of sulfite oxidase on conducting polyaniline film,” Synth. Met. 160 (2010).

[8] S. Koul, R. Chandra, S.K. Dhawan, "Conducting polyaniline composite for ESD and EMI at $101 \mathrm{GHz}$," Polym. Com. 41 (2000) 9305-9310.

[9] K. Nakajima, K. Kawabata, H. Goto, "Water soluble polyaniline/polysaccharide composite: Polymerization, carbonization to yield carbon micro-bubbles," Synth. Met. 194 (2014) 47-51.

[10] H. Goto, A. Yokoo, "Polyaniline nanospheres synthesized in the presence of polyvinyl alcohol followed by preparation of carbon nanobeads structures," J. Disp. Sci. Technol. 34 (2013) 406-410.

[11] C. Cifci, A. Kaya, "Preparation of poly(vinyl alcohol)/cellulose composite membranes for metal removal from aqueous solutions," Desalination 253 (2010) 175-179.

[12] J. J. Langer, S. Golczak, "Highly carbonized polyaniline micro- and nanotubes," Polym. Degr. Stab. 92 (2007) 330-334.

[13] Y. Gu, J. Huang, "Nanographite sheets derived from polyaniline nanocoating of cellulose nanofibers,” Mater. Res. Bulletin 48 (2013) 429-434.

[14] T. Moran, H.P. Hale, "Physics of the hen's egg I. Membranes in the egg," J. Exptl. Biol. 13 (1936) 35-40.

[15] Y. Guo, H. Zou, H. Wu, L. Zhou, H. Liu, X. Zhang, "Preparation of palladium membrane by bio-membrane assisted electroless plating for hydrogen separation," Int. J. Hydrogen Energy 39 (2014) 7069-7076.

[16] B.N. Aini, S. Siddiquee, K. Ampon, K.F. Rodrigues, S. Suryani, "Development of glucose biosensor based on $\mathrm{ZnO}$ nanoparticles film and glucose oxidase-immobilized eggshell membrane," Sensing and Bio-sensing Research 4 (2015) 46-56.

[17] Y. Zhang, G. Wen, Y. Zhou, S. Shuang, C. Dong, M.M.F. Choi, "Development and 
analytical application of an uric acid biosensor using an uricase-immobilized eggshell membrane," Biosens. Bioelectro. 22 (2007) 1791-1797.

[18] K. Suyama, Y. Fukazawa, Y. Umetsu, "A new biomaterial, hen egg shell membrane, to eliminate heavy metal ion from their dilute waste solution," Appl. Biochem. Biotech. 45/46 (1994) 871-879.

[19] B. Zheng, S. Xie, L.Qian, H. Yuan, D. Xiao, M.M.F. Choi, "Gold nanoparticles-coated eggshell membrane with immobilized glucose oxidase for fabrication of glucose biosensor," Sensors and Actuaters B 152 (2011) 49-55.

[20] Y. Gao, X. Li, J. Gong, B. Fan, Z. Su, L. Qu, "Polyaniline Nanotubes Prepared Using Fiber Mats Membrane as the Template and their Gas-response Behavior," J. Phys. Chem. C 112 (2008) 8215-8222.

[21] M. Liang, R. Su, W. Qi, Y. Yu, L. Wang, Z. He, "Synthesis of well-dispersed Ag nanoparticles on eggshell membrane for catalytic reduction of 4-nitrophenol," J. Mater. Sci. 49 (2014) 1639-1647.

[22] P.K. Kahol, N.J. Pinto, "Electron paramagnetic resonance investigations of electrospun polyaniline fibers," Solid State Commun. 124 (2002) 195-197.

[23] S.M. Yang, K.H. Chen, Y.F. Yang, "Synthesis of polyaniline nanotubes in the channels of anodic alumina membrane," Synth. Met. 152 (2005) 65-68.

[24] A.G. MacDiarmid, A.J. Epstein, “Secondary doping in polyaniline," Synth. Met. 69 (1995) 85-92.

[25] J.A. Marins, B.G. Soares, K. Dahmouche, S.J.L. Ribeiro, H. Barud, D. Bonemer, "Structure and properties of conducting bacterial cellulose-polyaniline nanocomposites," Cellulose 18 (2011) 1285-1294.

[26] H. Wang, E. Zhu, J. Yang, P. Zhou, D. Sun, W. Tang, "Bacterial cellulose nanofiber-supported polyaniline nanocomposites with flake-shaped morphology as supercapacitor electrodes," J. Phys. Chem. C 116 (2012) 13013-13019.

[27] S.H. Chung, A. Manthiram, "Carbonized Eggshell Membrane as a Natural Polysulfide Reservoir for Highly Reversible Li-S Batteries," Adv. Mater. 26 (2014) 1360-1365.

[28] H. Goto, J. Jwa, K. Nakajima, A. Wang, "Textile surface interfacial asymmetric polymerization,” J. Appl. Polym. Sci. 131 (2014) 41118.

[29] V. K. Kodali, S. A. Gannon, S. Paramasivam, S. Raje, T. Polenova, and C. Thorpe, "A novel disulfide-rich protein motif from avian eggshell membranes", PLoS One, 6, e18187 (2011). 